DEVELOPMENT OF ALTERNATIVE ENGINE MATERIALS

M. V. Nathal and S. R. Levine

NASA Lewis Research Center

Cleveland, $\mathrm{OH}$, USA 44135

\begin{abstract}
The purpose of this paper is to review the current state of development of new materials for advanced aircraft and aerospace engines. The advantages and disadvantages of ceramics and intermetallics in both monolithic and composite form as replacements for today's nickel-base superalloys are discussed. Results will be presented for research directed toward overcoming some of the problems which restrict the application of these alternative materials, along with some examples of materials which have reached the stage of component demonstration. It is concluded that while notable progress has been made toward solving many technical issues, the state of technology readiness is still immature when placed in a historical perspective with the introduction of new superalloy technology into aircraft engines. In addition to the need for further improvements in material properties, it is expected that a considerable time period will be needed to address issues related to cost, manufacturing, design, and competing technologies.
\end{abstract}


Historically, the development of the Ni-base superalloys has been integral to the improvements in efficiency and performance of gas turbine engines. These improvements, as measured by the creep-rupture strength of turbine blade materials, have increased at a relatively steady pace of approximately $100^{\circ} \mathrm{C}$ per decade since the $1940^{\prime} \mathrm{s}(1,2)$. These improvements have been achieved through a synthesis of design, process, and alloy development combined with a strong need for improved jet engine performance. It has now been 20 years since John Tien speculated at this conference on the "Celestial Limits" of superalloys(3). It is a tribute to superalloys that for the most part the alternatives to superalloys are still discussed in terms of 'potential' and 'barrier problems' rather than with stories of successful introduction into engines. Although improvements in superalloy properties and design concepts continue to increase engine performance and reliability, it is apparent that the physical limits of melting temperature and density of $\mathrm{Ni}$ will eventually limit engine performance. The needs for improved performance are still present, and new materials can provide improvements ranging from economic and performance benefits upon direct substitution, to cases where the new materials are enabling technologies, i.e., essential for a vehicle concept to be feasible.

The DOD and NASA have several programs actively investigating the development of alternative materials. Although these programs are frequently examining similar material systems, they are focussed on different vehicles and thus have different requirements for the engine materials, as summarized in Figure 1. Turbine materials in the Space Shuttle Main Engine are required to withstand severe thermal shocks plus exposure to hydrogen, but desired life is on the order of 50 hours(4). Hypersonic vehicles such as the National Aerospace Plane (NASP) also require high temperature materials with a resistance to a hydrogen environment, but material lifetimes for this demonstration vehicle are also short(5). The needs of advanced military planes are being addressed in the Integrated High Performance Turbine Engine Technology (IHPTET) program, and tend to emphasize higher temperatures and stresses but with relatively short lives, on the order of hundreds of hours(6). In contrast, commercial subsonic aircraft place a heavier emphasis on longer lives and fuel efficiency. A study of $21^{\text {st }}$ century subsonic transport using ultra-high bypass turbofan engines has predicted significant benefits from the use of advanced materials(7). The schematic diagram in Figure 2 shows alternative materials throughout such an engine. Much current emphasis from NASA is on a new generation supersonic transport, known as the High Speed Civil Transport(HSCT). This vehicle is expected to fly at speeds of Mach 2-3 over a range greater than 6000 nautical miles while carrying 250-300 passengers(8). This represents significant increases in performance over today's supersonic vehicles and advanced materials are required in order for this plane to be feasible(9). For such a vehicle to be viable, it must be environmentally acceptable and economically competitive. The former requirement mandates that the emissions of noise be at acceptable levels and that emissions of nitrous oxides ( $\mathrm{NO}_{\mathrm{x}}$ ) be minimized in order to avoid damage to the ozone layer. For the noise requirement, the engine contribution can be addressed via exhaust nozzle design. Since a very large nozzle near the tail of the aircraft is required, it is essential that lightweight, advanced high-temperature intermetallic matrix composites and ceramic matrix composites be developed. Such advanced materials could yield a 308 weight reduction compared to the current materials in a mixerejector nozzle design. Advanced concepts for control of $\mathrm{NO}_{\mathrm{x}}$ emissions in an HSCT require innovative combustor designs wherein conventional through-thewall film cooling is not possible. This results in a requirement for higher temperature materials with reasonably high levels of thermal conductivity. It appears that silicon-based ceramic matrix composites offer the greatest 


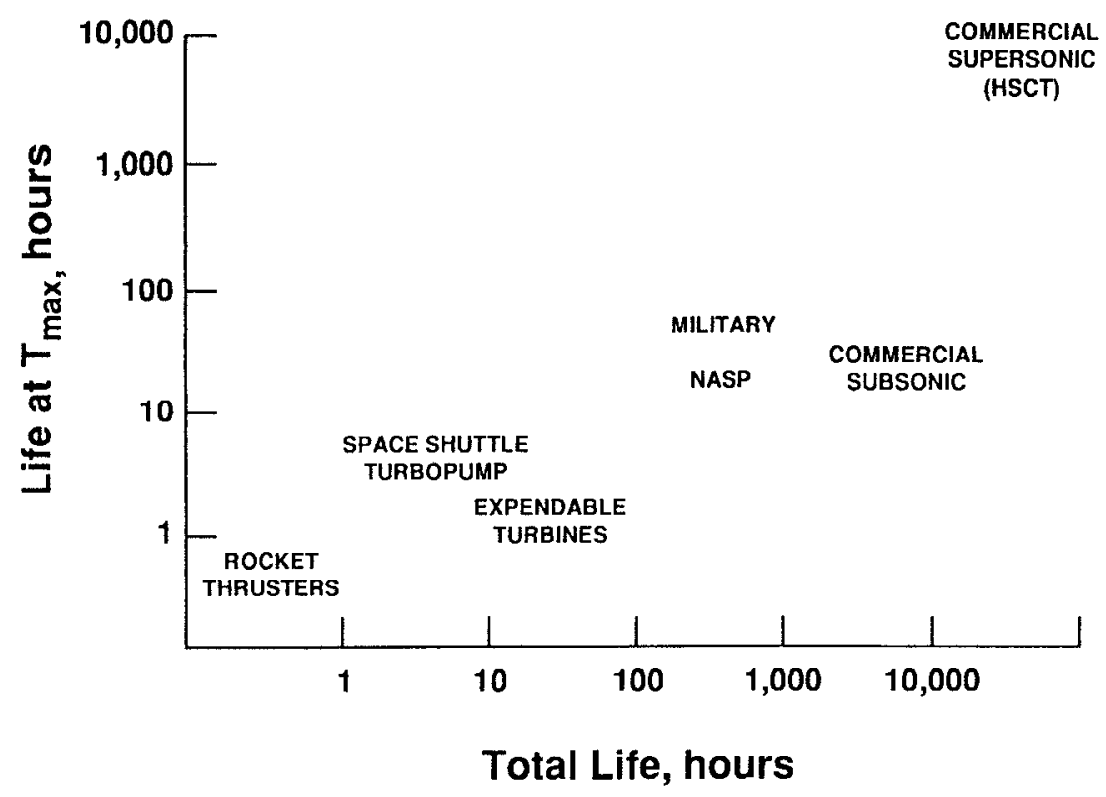

Figure 1. Approximate engine life requirements for various vehicles and demonstration programs.

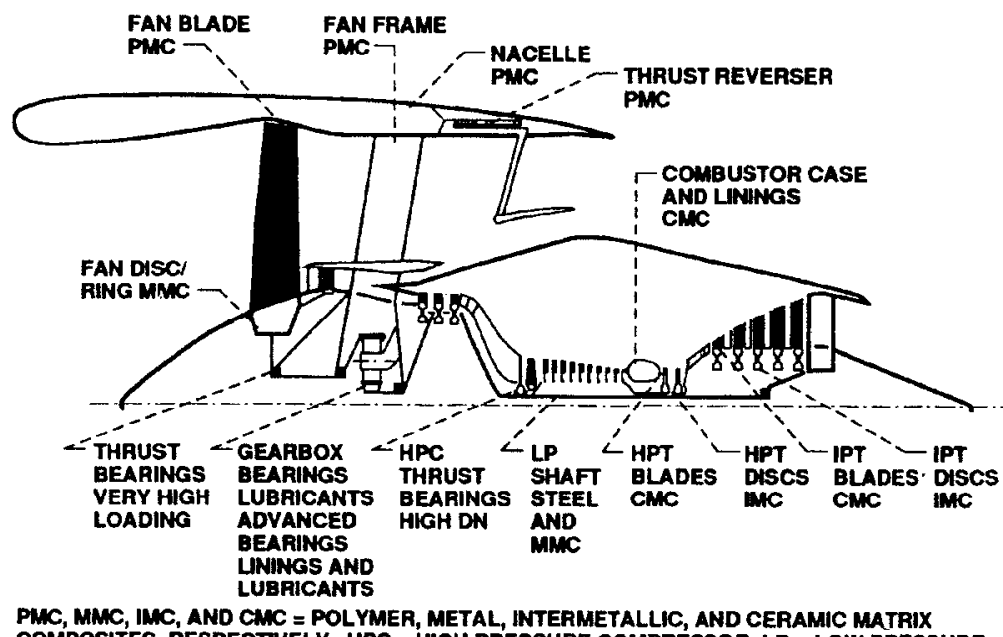

COMPOSITES, RESPECTIVLY. HPC = HIGH PRESSURE COMPRESSOR, LP = LOW PRESSURE, COMPOSITES, RESPECTVELY. HPC = HIGH PRESSURE COMPRESSOR, LP $=$ LOV
HPT $=$ HIGH PAESSURE TURBINE, IPT = INTERMEDIATE PRESSURE TURBINE.

Figure 2. Advanced materials applications for an ultra high bypass engine(4).

promise for such design concepts. Finally, the issue of economic viability translates not only to production costs, a major problem with advanced materials, but also to extended service lives, on the order of 18,000 hours of hot section life.

One strength of superalloys is that they possess a balance of the many properties required for engine application, Figure 3. In general, alternative materials show advantages in several of these properties but disadvantages in others. For example, ceramics offer large gains in temperature and specific strength capability but at a sacrifice of toughness, processability, and thermal conductivity. In comparison, intermetallics appear to offer smaller gains in performance but their other properties are closer to those of superalloys. This paper will present some of the ceramic and intermetallic materials under current investigation and will discuss their 


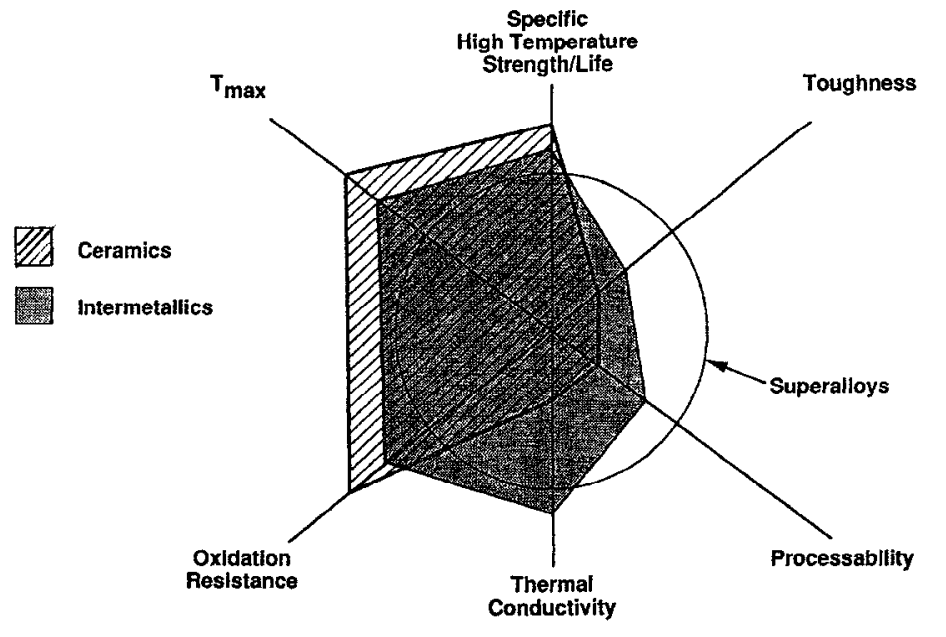

(a)

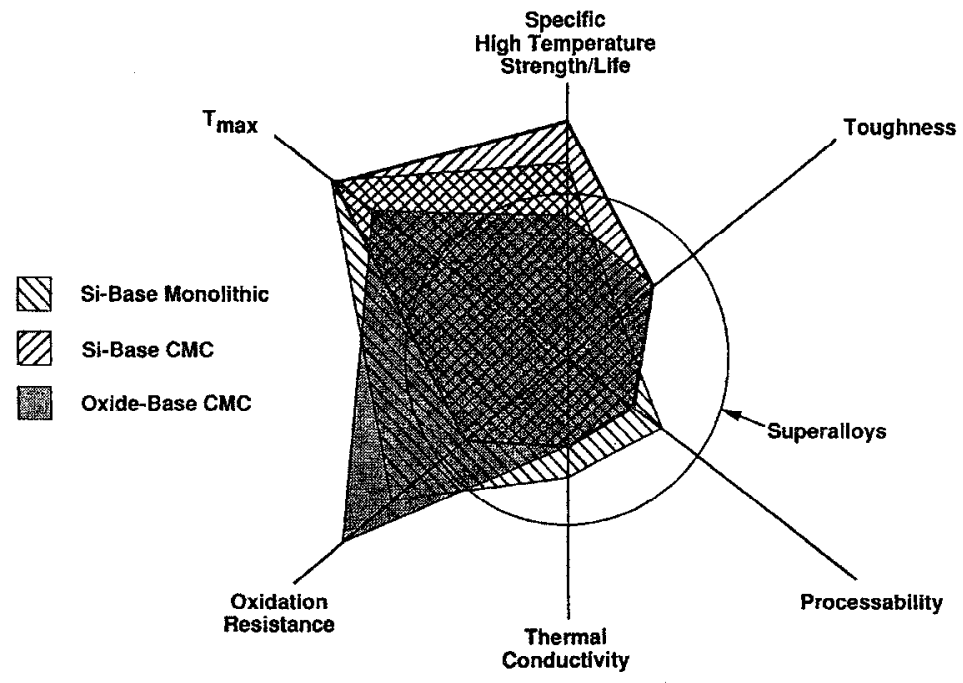

(b)

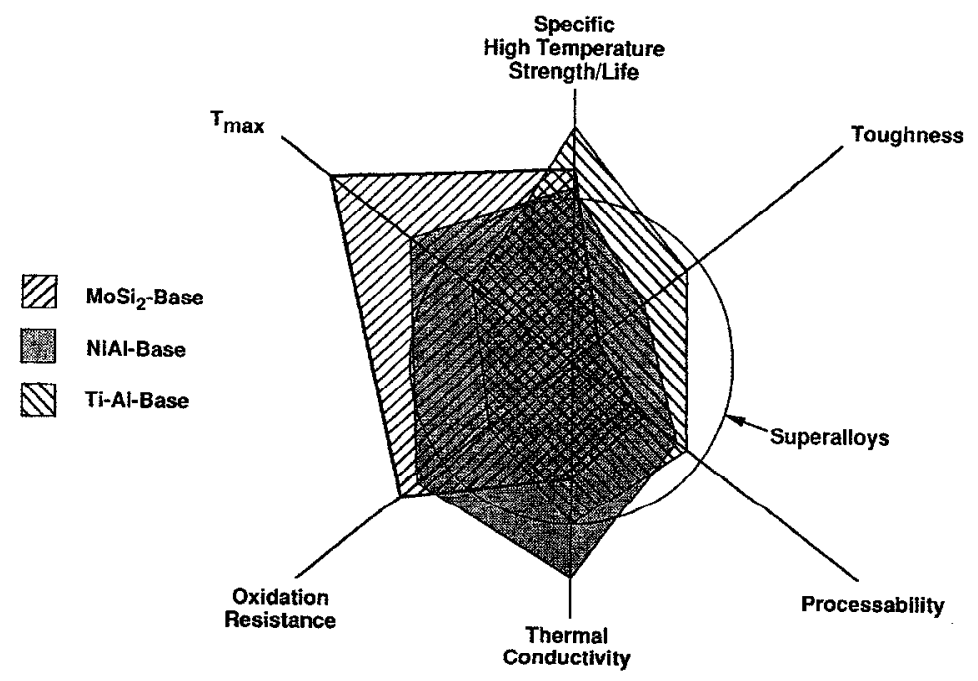

(c)

Figure 3. The balance of properties required for turbine engine application are represented by six axes. Generalizations of the properties of alternative materials are compared to those of superalloys. (a) an overall view of ceramics and intermetallics; (b) major subdivisions of ceramics; and (c) major subdivisions of intermetallics, including IMG's. 
potential for use in the various aircraft. Some of the key technical issues that need to be resolved will also be addressed.

\section{Alternative Materials}

\section{Ceramics}

Since the early 1970's when current generation ceramics efforts were born, the focus has been directed primarily at $\mathrm{SiC}$ and $\mathrm{Si}_{3} \mathrm{~N}_{4}$ monolithic ceramics(10). Intensive efforts on fiber reinforced ceramics (CMC's) did not get underway until about one decade later. Although ceramics remain inherently brittle with low resistance to flaws and overloads, significant progress has been made over this time period, and the benefits and examples of recent successes support the case for continued optimism.

The primary monolithic structural ceramics for heat engines are SiC and $\mathrm{Si}_{3} \mathrm{~N}_{4}$. In both materials large gains have been made in net shape fabrication capability, strength, creep resistance and fracture toughness $(10,11)$. SiC fracture toughness has been raised from about 3 to about $6 \mathrm{MPa}-\sqrt{\mathrm{m}}$ by alloying(12). $\mathrm{Si}_{3} \mathrm{~N}_{4}$ fracture toughness has been increased from levels of about 6 to about $10 \mathrm{MPa}-\sqrt{\mathrm{m}}$ by growth of elongated, interlocking $\mathrm{Si}_{3} \mathrm{~N}_{4}$ grains during the sintering process(13).

The primary applications for monolithic ceramics as structural gas turbine engine components are in small automotive and stationary gas turbines. In the consumer cost-driven automotive market, it is clear that superalloys cannot be applied from a cost standpoint even if superalloys with adequate properties could be developed to withstand the $1300-1400^{\circ} \mathrm{C}$ material temperatures required for efficiency in the absence of cooling. Currently, ceramics are capable of being fabricated with properties that meet design requirements. Design methodology, testing and joining capabilities are sufficient to build and run a ceramic gas turbine rotor for $100^{\prime} \mathrm{s}$ of hours $(11,14)$ and demonstration of the required 3500 hour life is forthcoming. Thus the next very major hurdle to be overcome is that of a tenfold cost reduction via economies in raw materials, fabrication, and machining. The DOE is taking the initiative in these areas.

Spin-offs from the automotive gas turbine developments are also being pursued in areas where material cost is less of a driver. Potential applications include auxiliary power units(15) and small gas turbine engines for propulsion and stationary power. Numerous successful rig and engine tests have been accomplished $(10,11)$. In these instances, ceramics can provide a significant upgrade in the performance and durability of small components, where risk is manageable and cooling is impractical or inefficient.

In aerospace systems, the fracture and reliability characteristics of monolithic ceramics and discrete particle-toughened ceramics limit their applications. Improved statistical reliability in as-fabricated materials is insufficient to assure the reliable performance of system components in service. The required functional reliability can be achieved by the use of fiber reinforcement to impart a 'graceful failure' characteristic to ceramics $(16,17)$. Graceful failure implies that matrix fracture can occur, but fibers bridge these cracks and continue to bear the structural loads. This bridging is expected to be optimized by the use of small diameter fibers, along with a fiber interface that is sufficiently strong for load transfer between fiber and matrix, yet sufficiently weak to deflect cracks from propagating from the matrix through fibers. The use of fibers that are stiffer and stronger than the matrix results in first fracture of the matrix at composite stress and strain levels beyond that of the unreinforced ceramic matrix. The first matrix fracture strength is often viewed as being 
analogous to the yield point in metals, and the design allowable strength can be based on some fraction of this value. These attributes of fiber reinforced CMC's significantly increase their functional reliability under severe service conditions and thus make it reasonable to consider their use in many critical aerospace applications.

Very demanding yet high pay-off applications for CMC's can be found in space power and aerospace vehicle propulsion systems. Here, gains related to weight reduction and improved temperature capability not only affect the efficiency of energy conversion, but are also multiplied throughout the system as a result of reduced fuel requirements, smaller tankage, and thus smaller overall vehicle size and mass. Several studies of the potential benefits possible from application of ceramics in rocket engine turbopumps have been carried out. Current performance of staged combustion and gas generator cycles are limited by the temperature capability of superalloys, and pump sizes are such that blade and vane cooling are impractical. Stateof-the-art CMC's offer the capability for more than a $300^{\circ} \mathrm{C}$ increase in cycle temperature. This can be used to provide increased performance and payload capability and improved durability via improved resistance to thermal shock and thermal fatigue. Significant progress is being made toward demonstrating the feasibility of CMG's for rocket propulsion applications. The ability of $\mathrm{CMC}$ 's such as chemically vapor infiltrated $\mathrm{C} / \mathrm{SiC}$ and $\mathrm{SiC} / \mathrm{SiC}$ to handle thermal shock and over-temperatures has been demonstrated(18), along with compatibility of SiC in a wet hydrogen environment(19). Plans are in place to demonstrate a small scale CMC hot stage consisting of a stator and rotor by 1995. Additionally, various CMC's have been demonstrated as exit cones(20), rocket nozzles(21), and small thrusters for satellite attitude adjustment(22).

Advanced aircraft gas turbine engines are another potential application where CMC's can yield major performance benefits. In aircraft, ceramic composites will be introduced in less demanding applications first, where temperatures and loads are relatively low. Examples are exhaust nozzle components and the tail cone, where weight reductions in these applications yield significant benefits. Recently CMC components fabricated by chemical vapor infiltration have been demonstrated. Inner exhaust nozzle flaps of $\mathrm{SiC} / \mathrm{SiC}$ and outer flaps of $\mathrm{C} / \mathrm{SiC}$ were installed in a Snecma M53 turbo-fan engine flown at the 1989 Paris Air Show(20). Oxide matrices reinforced with $\mathrm{SiC}$ fibers have also been considered, including $\mathrm{SiC} / \mathrm{Al}_{2} \mathrm{O}_{3}$ for combustors in unmanned turbine engines and for flameholders in a man-rated engine(21). Additionally, SiC reinforced lithium-aluminum-silicate shingle combustor liners have been studied to show the technical feasibility of obtaining a projected 258 life-cycle cost savings based on life equivalent to that of a metallic shingle concept(23). In general, the tests confirmed the potential of CMC's for these applications, although higher temperature capability would be required for actual use. Oxide/oxide ceramics based on sapphire fiber reinforcement have potential, but are currently limited by high temperature fiber strength and fiber coating development(24).

Many key issues need to be resolved for fiber reinforced ceramics to have major impact on aerospace systems by offering use temperatures significantly beyond that of metals. First, fiber producability, strength, and thermal stability need to be upgraded for both SiC and oxide fibers. These fiber properties are currently limiting the temperature capability of composites in terms of strength, creep resistance, and thermal stability. In the case of fiber development, there has been been significant recent progress. For example, the stability of Nicalon-type fibers has been improved by reducing oxygen content(25), and the high temperature strength of chemically vapor deposited SiC fibers have been improved(26). Second, mechanically tailored and oxidatively stable interphases between the fiber 
and matrix are required in order to achieve and maintain toughness and reliability. Progress in this area, however, has not been as rapid. In addition to upgrading the capability of the constituents, major efforts are needed in the areas of composite processing and manufacturing. It is of interest that all of the examples of component testing of CMC's discussed above involved infiltration processes to produce a near net shape. Finally, life prediction and design methodology, including joining and attachments, are in their infancies.

\section{Intermetallics}

Intermetallic compounds have been recognized as alternatives to superalloys since at least the 1950's(27), although interest has not been widespread until the last 5-10 years. Intermetallics in general do not have the temperature capability of ceramics but have advantages in ductility at the operating temperature, higher thermal conductivity, and better processability. The titanium aluminides based on $\mathrm{Ti}_{3} \mathrm{Al}\left(\alpha_{2}\right)$ and TiAl $(\gamma)$ have received the most attention based on their excellent density advantages over superalloys and higher temperature capability over Ti alloys. Because of the relatively early successes $(28,29)$ in improving ductility by adding $\mathrm{Nb}$, $\alpha_{2}$-based alloys have been studied continuously for over 20 years and have been considered for various applications in NASP and IHPTET. However, limitations in high temperature strength and environmental resistance are still present, although recent composition modifications to form high volume fractions of orthorhombic phase look more suitable(30,31). Continuous SiC fiber reinforcement appears to be the best means of achieving high temperature strength $(31,32)$, and reinforced rings are envisioned in various IHPTET engine tests. The development of $\gamma$-based materials with a balance of properties was not really achieved until recently(33), and this has sparked renewed interest in these materials. Most current applications for $\gamma$ are in monolithic form, as $\gamma$ is still too brittle to accommodate the differences in thermal expansion coefficient(CTE) with $\mathrm{SiC}$ fibers. $\mathrm{Al}_{2} \mathrm{O}_{3}$ fiber reinforcement of $\gamma$ is a more logical choice, although efforts seem limited at present. Despite the attractiveness of the Ti-base aluminides, they are still limited to intermediate temperature applications and are best suited for compressor components.

For the higher temperatures in the turbine section, NiAl and MoSi $i_{2}$ were identified as competitors to superalloys as early as 1952(34), although attaining ductility and toughness goals have remained elusive. Since the mid-80's, a wide variety of aluminides, silicides, beryllides, and other intermetallics have been examined in hopes of obtaining an understanding of which features control deformation and strength, and also of discovering new candidates for structural application. However, very few candidates appear to be able to achieve the balance of properties needed for engine application. Of particular note is the very short list of candidates that form protective oxide scales at high temperatures. Many silicides and trialuminides have very poor oxidation resistance in one or both of the intermediate and high temperature regimes(35). This again leads to a short list with NiAl and $\mathrm{MoSi}_{2}$ as the most serious candidates for application above $1000^{\circ} \mathrm{C}$.

NiAl has advantages over superalloys of density, thermal conductivity, and oxidation resistance that make it very attractive for turbine blade applications(36). Additionally, its ductile to brittle transition temperature (DBTT) is among the lowest of all intermetallics at about $400^{\circ} \mathrm{C}$. In all likelihood the creep resistance of NiAl will not be greatly different from that of superalloys, although the density savings in the blade can result in major savings throughout the rest of the engine(36). The recent progress $(36,37)$ in single crystal $\mathrm{NiAl}$, notably increased ductility upon $\mathrm{Fe}$ additions and increased creep resistance with Ti or Hf additions, have 
encouraged serious consideration of engine testing within the next few years. There are two other strategies that also show promise where different properties or different processing routes may be required. First is AlN dispersion strengthened NiAl, which is made by attrition milling NiAl in liquid nitrogen. This polycrystalline material also has competitive creep resistance to single crystal superalloys(38), although tensile properties have yet to be generated. This material can be extruded, and if processing advances to the point where other hot working procedures can be developed, a wide variety of applications may be considered. Finally, continuous $\mathrm{Al}_{2} \mathrm{O}_{3}$ fiber reinforcement of NiAl is under consideration(39). The use of a reinforcing fiber for strengthening allows for the optimization of the matrix composition for ductility. There are still major problems to be overcome, most notably the development of fiber coatings for a balance of strength, ductility, and thermal fatigue resistance, which is limited by CTE mismatch between fiber and matrix.

Because of the difficulties in surpassing the properties of superalloys with aluminides, attention is again directed towards silicides. Of the silicides, only $\mathrm{MoSi}_{2}$ has been studied to any degree, essentially because it has the best environmental resistance, including recent demonstrations that low temperature 'pesting' is not as severe as previously thought (40). Indeed, $\mathrm{MoSi}_{2}$ does have large advantages compared to superalloys, especially with respect to strength and oxidation resistance up to $1400^{\circ} \mathrm{C}(41)$. The more recent materials with reduced levels of $\mathrm{SiO}_{2}$ impurities have improved toughness and strength(42). However, this also raises the DBTT from approximately $1000^{\circ} \mathrm{C}$ to over $1300^{\circ} \mathrm{C}$. Thus, this silicide should be more accurately compared to Si-based ceramics, where $\mathrm{MoSi}_{2}$ is at a disadvantage in terms of density, oxidation, and strength but may have advantages in thermal conductivity and processability. Ductile phase reinforcement with refractory metal fibers has been successful in improving toughness values by over two orders of magnitude(43), although the issues of protecting the fibers from oxidation and from reaction with the matrix remain, especially for long life applications. $\mathrm{Al}_{2} \mathrm{O}_{3}$ has a matching CTE and is therefore an excellent choice for reinforcing $\mathrm{MoSi}_{2}(44)$.

\section{Historical Perspective}

It is also of interest to place the development of new materials in a historical context and to compare with some recent examples of introductions of new technology. The $\mathrm{Ni}$-base superalloys have seen continuous improvement for over 50 years and even with this broad experience base, it is still common to have a ten year period between the invention of a new alloy and its entry into service. With new, more unforgiving materials, longer times are needed for design integration and process scale-up. In the case of ceramics, the 'perfect' material has yet to be invented in over 20 years of research, yet in many cases the advantages of the ceramics can still be exploited by new design concepts. Comparatively, the intermetallics have just started to be examined. Early work in the $50^{\prime} \mathrm{s}$ and $60^{\prime} \mathrm{s}$ on $\mathrm{MoSi}_{2}$ and NiAl was discontinued, and was only reinstated in the mid-80's. The exception to this is the Ti aluminides, which have seen more steady development since the $70^{\prime} \mathrm{s}$ and not coincidentally are the closest to application. Given this time frame, it is not surprising that advanced materials have not achieved much success to date. Given the current increases in world-wide competition in the aerospace industry, however, there is even more pressure to reduce the time necessary for introduction of new technology(45).

In the case of oxide dispersion strengthened(ODS) alloys, the history(46) can be traced back to the first two decades of this century, when dispersion strengthened $W$ wires were developed, and also the beneficial effects of elongated grain structures were first demonstrated. Although TD- 
Ni was developed in the $1950^{\prime} \mathrm{s}$ by DuPont, it was not until the development of mechanical alloying(47) in the 1960's that ODS $\mathrm{Ni}$ alloys became a serious competitor as an engine material. Today, however, ODS alloys play a relatively minor role in jet engines, especially as a turbine blade material. This has been traced to at least three reasons(48). First, although there were improvements in some material properties, the behavior of alloys such as MA6000 was sufficiently different, especially the tendency for highly localized deformation, that unfamiliarity, which lead to a sense of unpredictability, caused a reluctance to consider this technology. Second, the sensitivity of these materials to processing variations caused numerous problems in scale-up and near net shape fabrication. And finally, during this same development period single crystal technology was improving so rapidly that the benefits of the ODS alloys were significantly diminished.

Another example is the introduction of single crystal superalloys for turbine blades $(49,50)$. The introduction of directionally solidified (DS) superalloys in military engines in 1969 and in commercial engines in 1974 signified a major improvement in metal and engine performance. The concept of stepping from DS to single crystals was put forward in the same time frame of the $60^{\prime} \mathrm{s}$, but interest was lacking due to the belief that the advantages over DS were not significant. The breakthrough concept of removing the grain boundary elements in order to widen the heat treatment window(51) and to allow new alloying additions was also available by about 1970 , but was not given notice due to the concurrent interest in other technologies, notably the work on DS eutectics. It was not for several more years, when the progress in eutectics was slowed, that single crystals were re-examined and more thorough data was generated to convincingly demonstrate the benefits. The first generation alloy PWA 1480 was then developed relatively rapidly, followed by two years of testing and development of production readiness, followed two years later with its introduction in commercial engines. In retrospect(50), the main barriers to introduction of this technology were business related, where reluctance was based on commitments to other technologies, pessimistic expectations of cost or performance, and simply some bad luck where failures of some early engine tests were coincidental with, but not caused by the single crystal blades. Once these barriers were overcome, the path to actual service went quickly. Scale-up to production was not a major problem, since one could build easily onto the existing DS technology. Of course, significant effort was still spent in defining new specifications, inspection standards, heat treatment scale-up, and trying to predict problems based on a limited experience base.

The last example is the use of thermal barrier coatings (TBC's) in critical locations in turbine engines $(52,53)$. The benefits of an insulating layer to protect metallic components from higher use temperatures were clearly recognized, and $\mathrm{TBC}^{\prime} \mathrm{s}$ were in common use on sheet materials in jet engines by the mid-60's. However, they were not seriously considered for more demanding applications, as most in the community questioned whether a ceramic coating could protect the more highly stressed turbine blades and vanes in a reliable, predictable fashion. In the mid-70's, the technical breakthroughs of switching to yttria-stabilized zirconia and the use of a single layer MCrAlY bond coat(54) were closely followed by a successful demonstration in a research engine(55). After this demonstration, ten years elapsed before TBC's were first made as bill of materials in a turbine section. Important developments during this time period consisted of independent confirmation of the first engine test results, optimization of compositions, improved deposition methods, and a constant effort to overcome skepticism regarding the reliability of the ceramic coatings. Today, problems still exist, primarily in the number of companies that can apply TBC's for the most critical applications, and in the continuous need for longer lives and more accurate life predictions. It is ironic, however, 
that TBC-coated superalloys (and perhaps intermetallics) have been developed and accepted to the point where they now represent the stiffest competition to other alternative materials $(50,56)$.

\section{Conclusions}

In the process of interviewing various individuals who were involved in the introduction of new technology into gas turbine engines in the past, several common themes emerged. First, every person was confronted by serious skepticism, from both internal management and from the outside community. In some cases, this skepticism can be healthy in that it requires a more rigorous testing of the new technology. However, there were several examples where the impact of a technical result was not recognized for long periods because of this skepticism. Difficulties in predicting where problems would arise were also common. Most of the problems that were expected based on past experience were the topics of development programs and were solved as progressive steps were made. However, unpredicted problems, such as the sensitivity of the ODS materials to processing procedures, delayed progress to the point where competing technologies surpassed them and became established. In general, the technical properties of the new technology are a necessary but not sufficient requirement for that technology to be used. In addition, issues relating to cost, demand, skepticism or unfamiliarity with the new technology, an adequate manufacturing base, or the timing in relationship to existing engine test schedules can all delay or prevent a new product from being used.

In the case of alternative materials, in many cases the technical properties have yet to be demonstrated and are still discussed in terms of 'potential' properties. Thus it is not surprising that skepticism $(56,57)$ is abundant and in many cases justified. However, it is also apparent that specific success stories are becoming more common, and several types of ceramics and intermetallics have matured to the point where engine tests and component manufacturing are either in progress or are being scheduled. In light of the many factors discussed above, the problems of meeting the requirements for specific components and of learning to design and fabricate unfamiliar materials are certainly well recognized and are being emphasized in current development programs. Additional factors such as an increased manufacturing base and continued evolutionary improvement of current materials may prove harder to overcome. There has also been some tendency to wind down the exploratory research where large numbers of materials are surveyed and to focus on fewer materials with more promise. As always, the difficult decisions revolve around the questions of how to evaluate 'potential' and how to focus finite resources.

\section{References}

1. R.F. Decker, in Proc. $4^{\text {th }}$ Int. Symp. on Superalloys, ed. by J.K. Tien, S.T. Wlodek, H. Morrow, M. Ge11, and G.E. Maurer, 1980, ASM, Metals Park, $\mathrm{OH}, \mathrm{p} .1$.

2. C.T. Sims, in Proc. 5th Int. Symp. on Superalloys, ed. by M. Gell, C.S. Kortovich, R.H. Brickne11, W.B. Kent, and J.F. Radavich, 1984, TMS-AIME, Warrendale, PA, p. 399.

3. J.K. Tien, in Proc. $2^{\text {nd }}$ Int. Symp. on Superalloys, 1972, Metals and Ceramics Information Center, Battelle, Columbus, OH, p. W-1. 4. J.R. Stephens, in AIAA'88: Proc. 24 th Joint Propulsion Conf., AIAA-883059,1988 , AIAA, Washington, D.C., p.1.

5. T.M.F. Ronald, Advanced Mat. \& Processes, May, 1989, p. 29.

6. D.M. Dimiduk, D.B. Miracle, and C.H. Ward, in High Temperature Intermetallics, Institute of Metals, 1991, p. 144. 
7. J.R. Stephens, in Metal and Ceramic Matrix Composites: Processing. Modelling, and Mechanical Behvior, ed. by R.B. Bhagat, A.H. Clauer, P.

Kumar, and A.M. Ritter, TMS, Warrandale, PA, 1990, p. 3..

8. J. Doychak, JOM, July, 1992, in press.

9. G.E. Allen, G.A. Champagne, H.L. Klein, and L.F. Schulmeister, NASA CR185246, Pratt and Whitney, 1990.

10. T.P. Herbell and W.A. Sanders, in Flight-Vehicle Materials, Structures, and Dynamics - Assessment and Future Directions, ed. by A.K. Noor and S.L.

Venneri, vol. 3, ASME, New York, 1992, in press.

11. P.W. Heitman, in Proc. $7^{\text {th }}$ Int. Symp. on Superalloys, ed. by S.D.

Antolovich, R.W. Stusrud, R.A. MacKay, D.L. Anton, T. Khan, R.D. Kissinger, and D.L. Klarstrom, TMS, Warrandale, PA, 1992, in press.

12. R.S. Storm, in Proc. $1^{\text {st }}$ Int. Symp. Science of Eng. Ceramics, ed. by $\mathbf{S}$.

Kimura and K. Niihara, Ceram. Soc. of Japan, Tokyo, 1991, p. 51.

13. C. Li and J. Yamanis, Ceram. Eng. Sci. Proc., vol. 10, 1989, p. 632.

14. P.J. Haley, ASME Paper 91-GT-367, 1991.

15. T. Bornemisza and C. Rodgers, SAE Tech. Paper 892254, 1989.

16. A.G. Evans, J. Am. Ceram. Soc., vol. 73, 1990, p. 187.

17. S.R. Levine, in Flight-Vehicle Materials, Structures, and Dynamics -

Assessment and Future Directions, ed. by A.K. Noor and S.L. Venneri, vol. 3, ASME, New York, 1992, in press.

18. T.P. Herbel1 and A.J. Ecke1, NASA TM 103743, 1991.

19. T.P. Herbe11, A.J. Eckel, and D.R. Hul1, in Environmental Effects on Advanced Materials, ed. by R.H. Jones and R.E. Ricker, TMS, Warrandale, PA, 1991 , p. 159.

20. R.F. Gilby, Design News, Nov. 1989, p. 104.

21. S. Ashley, Mech. Eng., July 1991, p. 44.

22. A.J. Ecke1, NASA Lewis Research Center, private communication, 1992.

23. D.J. Dubiel, R.P. Lohmann, S.Tanrikut, P.M. Morris, NASA CR 179534,

United Technologies Corp., 1986.

24. J.A. DiCar1o, in Flight-Vehicle Materials, Structures, and Dynamics -

Assessment and Future Directions, ed. by A.K. Noor and S.L. Venneri, vol. 4, ASME, New York, 1992, in press.

25. M. Takeda, Y. Imai, H. Ichikawa, T. Ishikawa, N. Kasai, T. Suguchi, and $\mathrm{K}$. Okamura, in Proc. 16 $6^{\text {th }}$ Annual Conf on Composites \& Advanced Ceramic

Materials, ed. by M.I. Mendelson, American Ceramic Society, Westerville, OH, 1992 , p. 209.

26. T. Schoemberg, Textron Specialty Materials, private communication, 1992 .

27. J.H. Westbrook, Mechanical Properties of Intermetallic Compounds, 1960, John Wiley and Sons, New York.

28. H.A. Lipsitt, in High Temperature Ordered Intermetallic Alloys, ed. by

C.C. Koch, C.T. Liu, and N.S. Stoloff, MRS Symp. vol. 39, p. 351.

29. M.J. Blackburn, D.L. Ruckle and C.E. Bevan, Report AFML-TR-78-18,

Wright Patterson Air Force Base, OH, 1978.

30. R.G. Rowe, in High Temperature Aluminides and Intermetallics, ed. by

S.H. Whang, C.T. Liu, D.P. Pope, and J.O. Stiegler, TMS, Warrandale, PA,

1990, p. 375 .

31. J.M. Larsen and P.R. Smith, in Proc. $7^{\text {th }}$ Int. Symp. on Superalloys, ed.

by S.D. Antolovich, R.W. Stusrud, R.A. MacKay, D.L. Anton, T. Khan, R.D.

Kissinger, and D.L. Klarstrom, TMS, Warrandale, PA, 1992, in press.

32. R.A. Mackay, P.K. Brindley, and F.H. Froes, JOM, May 1991, P.23

33. Y.W. Kim and D.M. Dimiduk, JOM, August 1991, p.40

34. W.A. Maxwe11, NACA RM E52D09, 1952

35. G.H. Meier, in Oxidation of High Temperature Intermetallics, ed. by $\mathrm{T}$.

Grobstein and J. Doychak, TMS, Warrandale, PA, 1988, p. 1.

36. R. Darolia, JOM, vo1. 43, 1991, p. 44.

37. R. Darolia, D. Lahrman, and R. Field, Scripta Metall., vol. 26, 1992, p. 1007 . 
38. J.D. Whittenberger, E. Artz, and M.J. Luton, J. Mat. Res., vol. 5, 1990 , p. 2819.

39. R.R. Bowman, in Intermetallic Matrix Composites II, ed. by D. Miracle, J. Graves and D.L. Anton, MRS Symp. 1992, in press.

40. P.J. Meschter, Metall. Trans., vol.23A, 1992, in press.

41. A.K. Vasudevan and J.J. Petrovic, in Proc. $1^{\text {st }}$ High Temperature Struc-

tural Silicides Workshop, Mat. Sci. Eng., 1992, in press.

42. R.M. Aikin, Scripta Metall., vol. 26, 1992, p. 1025.

43. H.E. Deve, C.H. Weber and M.J. Maloney, in Proc. $1^{\text {st }}$ High Temperature

Structural Silicides Workshop, Mat. Sci. Eng., 1992, in press.

44. M.J. Maloney and R.J. Hecht, in Proc. $1^{\text {st }}$ High Temperature Structural

Silicides Workshop, Mat. Sci. Eng., 1992, in press.

45. D.G. Backman and J.C. Williams, Science, vo1.235, 1992, p.1082.

46. G.B. Alexander and T.K. Glasgow, in Mechanical Properties of Metallic

Composites, ed. by S. Ochiai, 1992, Marcel Decker, Inc., New York, in press.

47. J.S. Benjamin, Metall. Trans., vo1. 6A, 1970, p. 2943

48. T.K. Glasgow, NASA Lewis Research Center, private communication, 1992.

49. M. Gell, D.N. Duhl, and A.F. Giamei, in Proc. $4^{\text {th }}$ Int. Symp. on Superal-

loys, ed. by J.K. Tien, S.T. Wlodek, H. Morrow, M. Ge11, and G.E. Maurer, 1980, ASM, Metals Park, OH, p. 205.

50. D.N. Duhl, Pratt and Whitney, private communication, 1992.

51. J.J. Jackson, M.J. Donachie, R.J. Henricks, and M. Ge11, Metal1.

Trans., vo1. 8A, 1977, p. 1615.

52. R.A. Miller, Surf. Coatings Tech., vol. 30, 1987, p. 1.

53. K.D. Sheffler and D.K. Gupta, J. Eng. Gas Turbines Power, vol 110, 1988, p. 605 .

54. S. Stecura, NASA TM-X-3425, 1976.

55. C.H. Liebert, et a1., NASA TM-X-3410, 1976.

56. C.T. Sims, Advanced Mat. \& Processes, June, 1991, p.32.

57. T.W. Eagar, Advanced Mat. \& Processes, June, 1991, p. 25. 